\title{
Use of the A2DS2 scale to predict morbidity in stroke-associated pneumonia: a systematic review and meta-analysis
}

\author{
Jie Huang ${ }^{1,2}$, Ming Liư ${ }^{1,2}$, Weiliang He², Feifei Liư ${ }^{3}$, Jinming Cheng ${ }^{2}$ and Hebo Wang ${ }^{1,2^{*}}$
}

\begin{abstract}
Background: This review aims to evaluate the performance and clinical applicability of the A2DS2 scale via systematic review and meta-analysis.

Methods: The Medline, Embase, Cochrane Library, CBM, CNKI, and Wanfang databases were searched. The risk of bias was assessed using the Quality Assessment of Diagnostic Accuracy Studies (QUADAS-2). Funnel plots and Egger's test were used to evaluate publication bias. The bivariate random-effect model was used for calculating the sensitivity, specificity, positive likelihood ratio, negative likelihood ratio, diagnostic odds ratio,

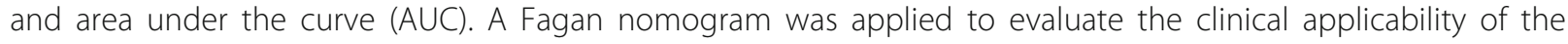
A2DS2 scale.

Results: A total of 29 full-text articles met the inclusion criteria, including 19,056 patients. Bivariate mixedeffects regression models yielded a mean sensitivity of 0.78 (95\% Cl: $0.73-0.83$ ), a specificity of 0.79 (95\% Cl: 0.73-0.84), a positive likelihood ratio of 3.7 (95\% Cl: 2.9-4.6), and a negative likelihood ratio of 0.27 (95\% Cl: $0.23-0.33$ ). The area under the receiver operating characteristic curve was 0.85 (95 \% Cl: 0.82-0.88). If given a pre-test probability of $50 \%$, the Fagan nomogram showed that when A2DS2 was positive, the post-test probability improved to $79 \%$. In contrast, when A2DS2 was negative, it decreased to $22 \%$. The results of the subgroup analysis showed no effect on the diagnostic accuracy of the A2DS2 scale in predicting stroke-associated pneumonia, except for the optimal cut-off value.
\end{abstract}

Conclusions: The A2DS2 scale demonstrates high clinical applicability and could be a valid scale for the early prediction of stroke-associated pneumonia in stroke patients.

Keywords: A2DS2 scale, Stroke-associated pneumonia, Stroke, Meta-analysis

\footnotetext{
* Correspondence: wanghbhope@hebmu.edu.cn

${ }^{1}$ North China University of Science and Technology, Tangshan, Hebei, China

${ }^{2}$ Department of Neurology, Hebei General Hospital, 050000 Shijiazhuang, Hebei, China

Full list of author information is available at the end of the article
}

(C) The Author(s). 2021 Open Access This article is licensed under a Creative Commons Attribution 4.0 International License, which permits use, sharing, adaptation, distribution and reproduction in any medium or format, as long as you give appropriate credit to the original author(s) and the source, provide a link to the Creative Commons licence, and indicate if changes were made. The images or other third party material in this article are included in the article's Creative Commons licence, unless indicated otherwise in a credit line to the material. If material is not included in the article's Creative Commons licence and your intended use is not permitted by statutory regulation or exceeds the permitted use, you will need to obtain permission directly from the copyright holder. To view a copy of this licence, visit http://creativecommons.org/licenses/by/4.0/. The Creative Commons Public Domain Dedication waiver (http://creativecommons.org/publicdomain/zero/1.0/) applies to the data made available in this article, unless otherwise stated in a credit line to the data. 


\section{Background}

Stroke-associated pneumonia (SAP) is a common medical complication of stroke that affects $5.60-37.98 \%$ of stroke patients [1]. Delays in the diagnosis or treatment of SAP increase disease mortality, prolong the length of hospital stay, and increase medical costs. Therefore, it is necessary to find an early and reliable method to predict the risk of SAP. However, previous research usually focuses on diagnosing pneumonia or stroke rather than SAP prediction [2].

In recent years, various risk factors for SAP have been reported. SAP risk factors include mechanical ventilation, atrial fibrillation, pre-existing respiratory disease, smoking, pre-existing heart disease, and dysphasia [3]. Combined with the SAP risk factors, some researchers in different regions established several early prediction SAP scales, such as the A2DS2 scale and the PANTHERS scale in Germany, the ISAN scale in Britain, and the AIS-APS scale in China [47]. Indeed, potential deficiencies existed among the different scales, such as their use of various sources, the need for continuous external validation, and their complexity. The A2DS2 scale predicts SAP better than other platforms [8], however, the clinical adaptability of the A2DS2 scale has not been comprehensively and systematically analysed until now.

The A2DS2 scale is one of the most widely used rankings and has been extensively used in the clinic. The A2DS2 scale was developed by Hoffmann et al. and was based on a clinical scale for evaluating SAP after stroke in 15,335 stroke patients in Germany [4]. Multivariate analysis was used to analyse its risk factors and to assign points to form the A2DS2 scale. In this study, the A2DS2 scale had a high sensitivity (83\%) and specificity (72 \%). However, another study conducted in China reported that the sensitivity and specificity of the A2DS2 scale were $69 \%$ and $73 \%$, respectively [9]. Other studies also reported different sensitivities and specificities, which may be related to race, incidence, research methods, and the optimal cut-off value of the scale. Therefore, quantifying and comparing the clinical differences of trials within a meta-analysis is crucial to determining the applicability and use of the ASD2 scale in clinical practice.

This meta-analysis provides evidence for the evaluation and diagnosis of SAP by the A2SD2 scale and verifies its clinical applicability. Appropriate interventions can be combined with predictive outcomes to reduce the risk of SAP.

\section{Methods}

Data sources and search strategies

Systematic retrieval of literature up to June 2020 in PubMed, Embase, the Cochrane Library, Web of Science, the China National Knowledge Infrastructure database, and the Wanfang database was conducted. The following search terms were used in combination: (( "strokes" OR "cerebrovascular accident" OR "brain vascular accident" OR "apoplexy") AND ("stroke-associated pneumonia" OR "experimental lung inflammation" )) AND ( "A2DS2 scale" OR "score" ).

1109 references were found in the database

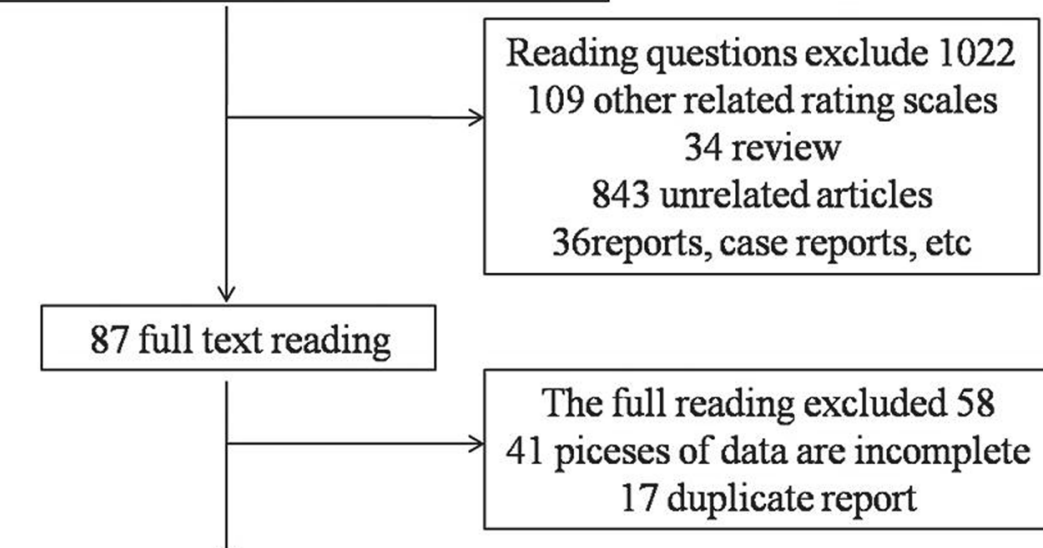

A total of 29 articles were included for meta-analysis

Fig. 1 Flow diagram of the study selection process 


\section{Inclusion criteria}

The inclusion criteria were as follows: (1) prospective or retrospective clinical studies; (2) patients diagnosed with stroke; (3) patients met the diagnostic criteria for pneumonia [10-12] and stroke [13]; and (4) the true positive value, false positive value, true negative value and false negative value of the A2DS2 scale could be obtained directly or indirectly to predict pneumonia in patients with stroke.

\section{Exclusion criteria}

The exclusion criteria were as follows: (1) studies reporting duplicated results; (2) other scales for predicting SAP; (3) studies with low quality or unavailable data; (4) studies with a gold-standard diagnosis; and (5) reviews, letters, editorials, letters, and case reports.

\section{Data extraction}

Two researchers extracted data independently, including the first author, year of publication, population, patient diagnosis standard, research type, sample size, four types of data (true positive (TP), false positive (FP), true negative (TN), and false negative (FN)) and their degrees of sensitivity and specificity.

\section{Quality assessment}

We assessed the quality of the included studies with the QUADAS-2 checklist [14]. The scale included 14

Table 1 Baseline characteristics of studies that satisfied the inclusion criteria (TP $=$ true positive, $F P=$ false positive, $T N=$ true negative, $\mathrm{FN}=$ false negative)

\begin{tabular}{|c|c|c|c|c|c|c|c|c|c|}
\hline Author & Region & Year & Type & Sample size & TP & FP & $\mathrm{FN}$ & $\mathrm{TN}$ & The values of the A2DS2 \\
\hline Yang L [15] & China & 2019 & retrospective & 2552 & 138 & 637 & 62 & 1715 & 4 \\
\hline Ren XY [16] & China & 2019 & retrospective & 530 & 75 & 89 & 15 & 351 & 5 \\
\hline Yang R [17] & China & 2019 & prospective & 86 & 16 & 18 & 3 & 49 & 5 \\
\hline Mao BY [18] & China & 2018 & prospective & 80 & 44 & 7 & 1 & 28 & 5 \\
\hline Zhang Y [9] & China & 2017 & retrospective & 2552 & 162 & 889 & 37 & 1464 & 3 \\
\hline Pi CX [19] & China & 2019 & retrospective & 215 & 31 & 18 & 13 & 153 & 5 \\
\hline Wang N [20] & China & 2018 & prospective & 271 & 85 & 15 & 18 & 153 & 5 \\
\hline Hang J [21] & China & 2017 & retrospective & 1472 & 257 & 158 & 138 & 874 & 5 \\
\hline Luo XN [22] & China & 2018 & retrospective & 203 & 27 & 19 & 19 & 138 & 4.5 \\
\hline Zhang YP [23] & China & 2019 & retrospective & 201 & 24 & 27 & 7 & 143 & 7 \\
\hline Shan Y [24] & China & 2018 & retrospective & 252 & 27 & 19 & 20 & 186 & 6.5 \\
\hline Yuan Y [25] & China & 2018 & retrospective & 512 & 61 & 57 & 24 & 427 & 4 \\
\hline Yang JF [26] & China & 2014 & retrospective & 636 & 80 & 64 & 12 & 480 & 7 \\
\hline Zhang XP [1] & China & 2016 & retrospective & 1239 & 57 & 174 & 33 & 975 & 5 \\
\hline Shang YC [27] & China & 2013 & retrospective & 131 & 30 & 23 & 8 & 70 & 5 \\
\hline Li Y [28] & China & 2014 & prospective & 1142 & 130 & 70 & 85 & 857 & 5 \\
\hline Gong SY [29] & China & 2016 & retrospective & 1569 & 168 & 455 & 72 & 874 & 3 \\
\hline Lu Y [30] & China & 2015 & prospective & 101 & 49 & 17 & 2 & 33 & 5 \\
\hline Li L [31] & China & 2014 & retrospective & 1279 & 198 & 78 & 110 & 893 & 10 \\
\hline Batubara CA [32] & Indonesia & 2015 & retrospective & 32 & 20 & 6 & 2 & 4 & 5 \\
\hline Limesh V [33] & India & 2019 & prospective & 250 & 44 & 71 & 2 & 133 & 5 \\
\hline Tu TM [34] & Singapore & 2017 & retrospective & 731 & 36 & 173 & 4 & 518 & 7 \\
\hline Zapata AE [35] & Spain & 2017 & prospective & 201 & 27 & 86 & 4 & 84 & 5 \\
\hline Ramírez-Moreno J.M [36] & Spain & 2016 & prospective & 224 & 30 & 31 & 15 & 209 & 6 \\
\hline Yota K [37] & Japan & 2019 & retrospective & 111 & 14 & 26 & 3 & 68 & 5 \\
\hline Nam KW [2] & Korea & 2017 & retrospective & 299 & 24 & 38 & 18 & 219 & 5 \\
\hline Cugy E [38] & French & 2017 & retrospective & 1960 & 126 & 365 & 43 & 1426 & 5 \\
\hline Helmy TA [39] & Egypt & 2016 & prospective & 70 & 20 & 7 & 6 & 37 & 6 \\
\hline HElhasina [40] & Arab & 2019 & prospective & 200 & 37 & 134 & 5 & 24 & 5 \\
\hline
\end{tabular}


items divided into four parts, including case selection, trial to be evaluated, gold standard, and process cases. The deviation risk level was determined based on the answers to the questions. Eligibility was agreed upon, and any disagreements were resolved through discussion and mutual consensus.

\section{Statistical analysis}

STATA 12.0 was used for statistical analysis. Interstudy heterogeneity was tested using the $\mathrm{I}^{2}$ test, with an $\mathrm{I}^{2}>$ $75 \%$ denoting heterogeneity. The outcome parameters were overall sensitivity, specificity, positive likelihood ratio (PLR), negative likelihood ratio (NLR), diagnostic odds ratio (DOR), and their corresponding $95 \%$ confidence intervals (CIs) by a random-effects model. Each included study's sensitivity and specificity were used to plot the summary ROC (SROC) curves and to calculate the area under the SROC curve (AUC). The PLR and NLR were used to calculate the clinical utility of the A2DS2 scale. The diagnostic odds ratio (DOR) was used as the summary measure of diagnostic accuracy. Sensitivity analysis was performed

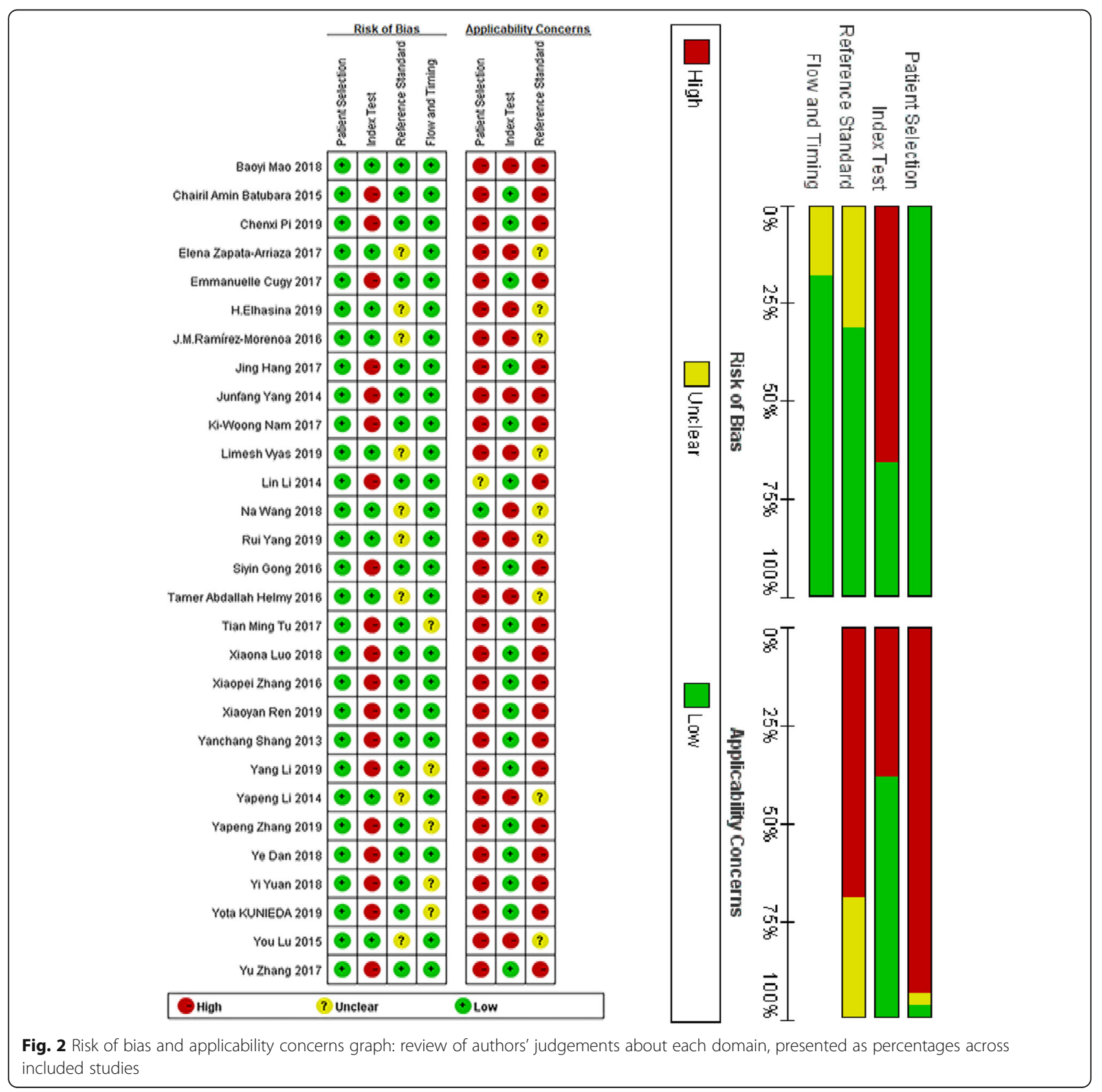


according to the missing data, risk of bias, and sample size to evaluate the robustness of significant statistical heterogeneity. Subgroup analysis demonstrated whether ethnicity, study type and cut-off value affected the diagnostic accuracy. Deeks' funnel plot and Egger's test were used to detect publication bias, with $P<0.05$ indicating publication bias. The clinical applicability of the A2DS2 scale was evaluated by constructing a Fagan nomogram with combined positive and negative likelihood ratios.

\section{Results}

\section{Search results and quality evaluation}

Initially, 1569 articles were retrieved; according to the inclusion and exclusion criteria, 29 studies were ultimately included in this study. A screening flowchart of the course is depicted (Fig. 1). Of these 29 studies, 10 were prospective studies, and 19 were retrospective studies. The specific information for each study is shown in Table 1. A total of 19,056 stroke patients were analysed, with the populations coming from different countries. The included subjects had a low risk of migration and high clinical adaptability (Fig. 2). The study characteristics of the data sets are listed in Table 1.

\section{Diagnostic accuracy of the A2DS2 scale}

Meta-analysis showed that the merged sensitivity, specificity, DOR (Fig. 3) and AUC (Fig. 4) of the A2DS2 scale were 0.78 (95 \% CI: $0.73-0.83 ; P=$

\begin{tabular}{|c|c|c|c|c|c|c|c|c|}
\hline Study & $i$ & SENSTMTY (155\% CC) & Studyd & i] & SPECFICTTY (15\% CC) & Studyld & 1 & ODDS RATIO (95\% Cl) \\
\hline HElhasina & $y$ & $0.88[0.74-0.96]$ & HEhasina & Ii & $0.15[0.10-0.22]$ & HEhasina & y & $133[0.47-371]$ \\
\hline Tames Abdolah Helmy & th & $0.77[0.56-0.91]$ & Tamer Abdalah Helmy & 3 & $0.840 .70-0.93$ & Tamer Abdallah Helny & 4 & $1762[521.59591$ \\
\hline Emmanuele Cugy & 1 & $0.75[0.67 \cdot 0.81]$ & Emmanuele Cugy & 1 & $0.80[0.78 \cdot 0.81]$ & Emmanuelle Cugy & i & $11.45[7.95 \cdot 16.49]$ \\
\hline K. Woong Nam & $s_{1}^{2}$ & $0.57[0.41-0.72]$ & K.-Woong Nam & 1 & $0.85[0.80-0.89]$ & K.-Woong Nam & $y$ & $7.68[3.81-15.50]$ \\
\hline Yota KUNEEOA & +1 & $0.82[0.57 \cdot 0.56]$ & Yota KUNEDA & 1 & $0.72[0.62 \cdot 0.81]$ & Yota KUNIEDA & 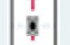 & $12.21[3.24-45.98]$ \\
\hline JMR Ramirez-Norenos & $i$ & $0.67[0.51 \cdot 0.000]$ & JMRamirez-Horenos & 8 & $0.87[0.82 \cdot 0.91]$ & J.M.Ramirez-Morenoa & i & $13.48[6.53-27.86]$ \\
\hline Elena Zapala-Ariaza & 1 & $0.87[0.70-0.56]$ & Elena Zappla-Ariaza & it & $0.49[0.42 \cdot 0.57]$ & Elena Zapata-Arriaza & $t$ & $6.59[2.21-19.65]^{\circ}$ \\
\hline Tran Ning Tu & 8 & $0.90[0.76 \cdot 0.97]$ & Tinn $N$ ing Tu & $\theta$ & $0.75[0.72 \cdot 0.78]$ & Tran King Tu & 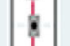 & $26.95[9.46-7679]$ \\
\hline Limesh Wyas & a & $0.96[0.85 \cdot 0.99]$ & Limesh Wyas & 1 & $0.65[0.58-0.72]$ & Limesh Wyas & 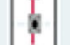 & $41.21[9.71-174.99]$ \\
\hline Chain Amin Batubara & a & $0.91[0.71 \cdot 0.996]$ & Chain Amin Batudara & 8 & $0.40[0.12 \cdot 0.74]$ & Chairl Amin Batubara & $\$$ & $6.67[0.97-45.79]$ \\
\hline Linti & 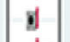 & $0.64[0.59 \cdot 0.70]$ & Lin & 8 & $0.92[0.90-0.94]$ & Lin Li & i & $20.61[14.84-28.62]$ \\
\hline Youlu & 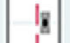 & $0.56[0.87-1.00]$ & Youlu & 1 & $0.66[0.51-0.79]$ & Youlu & 4 & $47.56[10.30-219.68]$ \\
\hline Sijn Gong & 1 & $0.70[0.64-0.76]$ & Sign Gong & 1 & $0.66[0.63-0.68]$ & Sivin Gong & 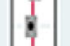 & $4.48[3.33-6.04]$ \\
\hline Yapengli & $\theta_{1}$ & $0.60[0.54 \cdot 0.67]$ & Yapengli & $i$ & $0.92[091-0.94]$ & Yapeng Li & 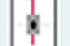 & $18.72[12.98-27.01]$ \\
\hline Yanchang Sháng & $\$$ & $0.79[0.63-0.90]$ & Yanthang Sháng & 8 & $0.75[0.65-0.84]$ & Yanchang Shang & 8 & $11.41[4.59-28.39]$ \\
\hline Xeopee ithang & 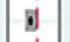 & $0.63[0.53-0.73]$ & Xocope ithang & 1 & $0.85[0.83 \cdot 0.87]$ & Xaopeizhang & 8 & $9.68[6.12-15.30]^{\circ}$ \\
\hline Juniang Yang & 8 & $0.87[0.78-0.935]$ & Juliang Yamg & 8 & $0.8[085-0.91]$ & Junfang Yang & 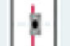 & $50.00[25.83-95.78]$ \\
\hline YiYuan & 1 & $0.72[0.61 \cdot 0.81]$ & YiYuzon & $\theta$ & $0.80[0.85-0.91]$ & YiYuan & a & $19.04[11.02 \cdot 32.91]$ \\
\hline Ye Dan & $z_{1}$ & $0.57[0.42 \cdot 0.72]$ & Yedan & i & $0.91[0.86-0.84]$ & Ye Dan & $x$ & $13.22[6.26-27.88]^{2}$ \\
\hline Yapeng Zlhang & $i$ & $0.77[0.59 \cdot 0.90]$ & Yapeng Zlang & 1 & $0.84[0.78 \cdot 0.089$ & Yapeng Zhang & 8 & $18.16[7.11 \cdot 46.35]$ \\
\hline Xeonaluo & 界 & $0.59[0.43 \cdot 0.73]$ & Xoonaluo & a & $0.8[0.82 \cdot 0.93]$ & Xiaona Luo & 8 & $10.32[4.84-22.02]$ \\
\hline Jing Hang & a & $0.65[0.60-0.70]$ & Ing Hang & 1 & $0.85[082 \cdot 0.87]$ & Jing Hang & 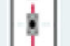 & $10.30[7.88-13.46]$ \\
\hline Na Wang & 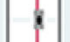 & $0.83[0.74 \cdot 0.89]$ & Nällang & $\theta$ & $0.91[0.86-0.56]$ & NaWang & 6 & $48.17[23.10-100.42]$ \\
\hline Chenxip & 1 & $0.70[0.56 \cdot 083]$ & Chenxif & $\theta$ & $089[0.84 \cdot 0.44]$ & Chenxi Pi & 8 & $20.27[9.01-45.62]$ \\
\hline YuZhang & 8 & $0.81[0.75 \cdot 0.87]$ & YuZlhang & 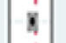 & $0.62[0.60-0.64]$ & Yu Zhang & 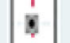 & $7.21[5.00-10.40]^{\circ}$ \\
\hline Bosojillao & I & $0.88[0.8-1.00]$ & Bosojillaso & 8 & $0.00[0.63-0.92]$ & Baoji Mao & 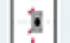 & $176.00[20.54-1000.00]$ \\
\hline RuiYang & -1 & $0.84[0.60-0.97]$ & Rúlang & 1 & $0.73[0.61 \cdot 0.83]$ & RuiYang & 1 & $14.52[3.78-55.79]$ \\
\hline Xicojan Ren & $i$ & $0.83[0.74 \cdot 0.90]$ & Xisojan Ren & 1 & $0.80[0.76-0.83]$ & Xizoyan Ren & 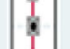 & $19.72[10.81 \cdot 35.97]$ \\
\hline Yangli & 1 & $0.69[0.62 \cdot 0.75]$ & Yang i & 1 & $0.73[0.71 \cdot 0.75]$ & Yangli & 4 & $5.99[4.38-8.20]$ \\
\hline COMBNED & $\begin{array}{l}1 \\
1 \\
1 \\
1 \\
1\end{array}$ & $\begin{array}{l}0.780 .73 \cdot 0.83] \\
Q=15208, d i=28.00, p=0.000 \\
D=81.59[75.50 \cdot 87.60]\end{array}$ & COUBNED & $\begin{array}{l}1 \\
1 \\
1 \\
1 \\
\end{array}$ & $\begin{array}{l}0.790 .73-0.84] \\
0=162202,01=2800, p=0.000 \\
{[2=98.27[9800 \cdot 98.56]}\end{array}$ & COMBINED & $\begin{array}{l}1 \\
1 \\
1 \\
1\end{array}$ & $\begin{array}{l}13.43[10.06-17.92] \\
Q=1.1 e+15, d f=28.00, p=0.00 \\
12=100.00[100.00-100.00]\end{array}$ \\
\hline & $\begin{array}{l}0.41 .0 \\
\text { sas }\end{array}$ & & & $\begin{array}{l}0.09 \\
\text { setror }\end{array}$ & & & 0000 & \\
\hline
\end{tabular}




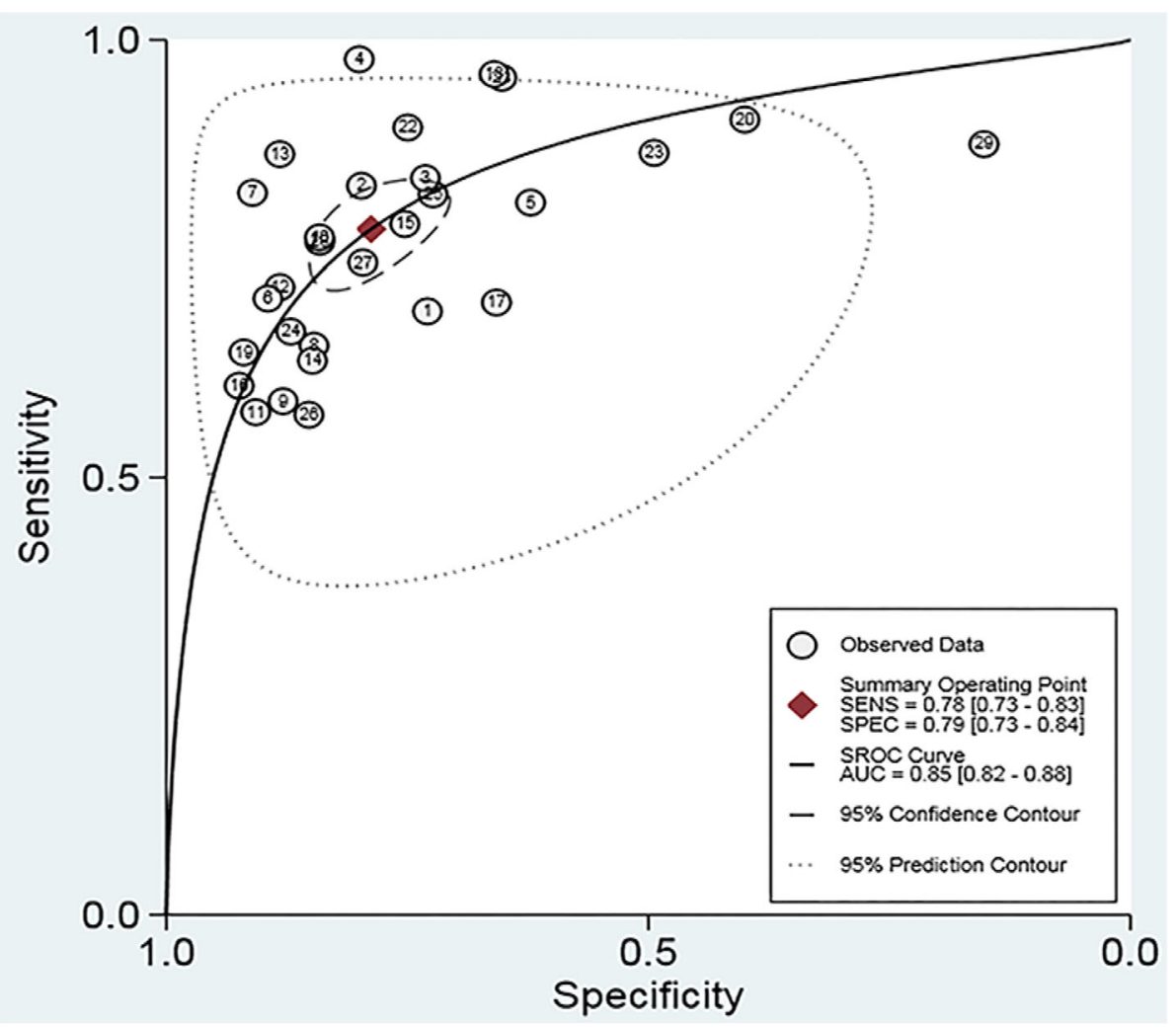

Fig. 4 Summary receiver operating characteristic curve showing the $95 \%$ confidence contour and $95 \%$ prediction contour

0.00), 0.79 (95 \% CI: $0.73-0.84 ; P=0.00), 13.43$ (95 \% CI: $10.06-17.92 ; P=0.00)$ and $0.85(95 \% \mathrm{CI}$ : $0.82-0.88)$, respectively.

According to the sensitivity analysis (Fig. 5), the combined DOR did not change significantly before and after each study was individual excluded, indicating that the study results were stable. The funnel plot showed the symmetry of the studies included in our meta-analysis (Fig. 6). The $p$-value of Egger's test was 0.19 , indicating that there was no publication bias in the study. Fagan nomogram analysis showed that the preset a priori probability of A2DS2 was $50 \%$, and the predictive diagnostics of A2DS2 were complimentary. The likelihood of stroke patients being diagnosed with stroke-related pneumonia rose to $79 \%$, and the negative prediction of A2DS2 fell to $22 \%$, indicating good adaptability and clinical diagnosis of the A2DS2 scale (Fig. 7).

Subgroup analyses were conducted to determine whether ethnicity, study type and cut-off value were sources of heterogeneity affecting the scale's diagnostic accuracy. The subgroup analysis results did not affect the diagnostic accuracy of the A2DS2 scale in predicting SAP, except for the cut-off value (Table 2). A cut-off value greater than 5 had a sensitivity of $0.75(0.64,0.83)$ and a specificity of $0.87(0.80,0.91)$. Those with less than 5 points and those with 5 points had sensitivities of $0.71(0.65,0.77)$ and $0.79(0.73$, $0.84)$ and specificities of $0.76(0.670 .69,0.83)$ and 0.76 $(0.68,0.82)$, respectively.

\section{Discussion}

In recent years, some successful management and treatments of acute stroke have emerged. However, stroke remains the leading cause of death worldwide, among which stroke with complications of pneumonia is a critical cause of increasing mortality [41]. It is necessary to assess SAP risk at an early stage; unfortunately, the early diagnosis standards are still not unified. Commonly used scales include the A2DS2 scale, the PANTHERIS score, the ISAN score and the AIP-APS score, but the PANTHERIS score [5] and AIP-APS score [7] require laboratory test results, which further increases the difficulty in the early evaluation of SAP. Researchers have indicated 


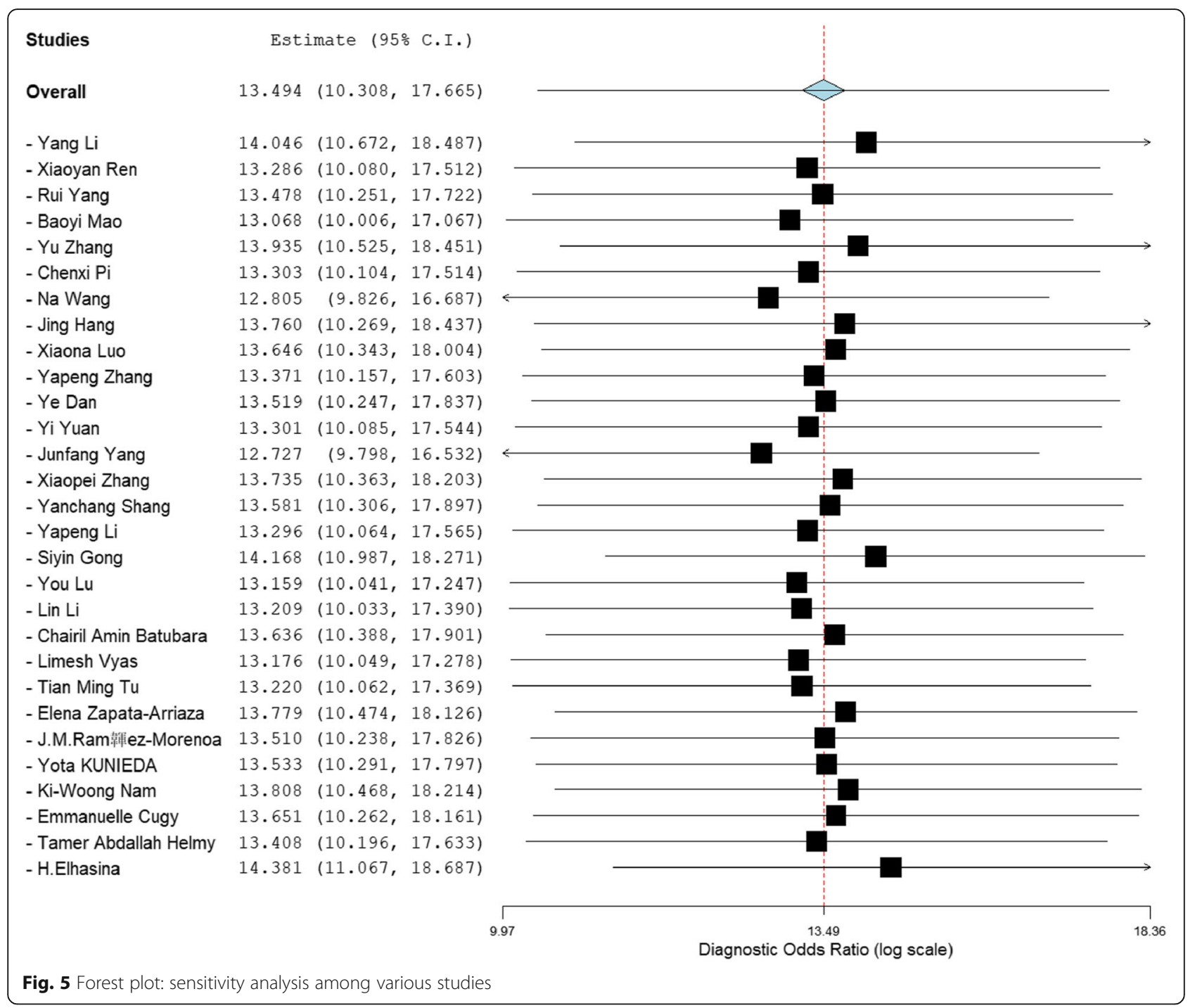

that the A2DS2 scale has a higher c-statistic value than other scales, though its external validation method and specific clinical efficacy need to be verified.

The results of this meta-analysis showed that the AUC of the A2DS2 scale was 0.85 (95 \% CI: 0.82, 0.88 ) for predicting stroke-associated pneumonia, and the sensitivity and specificity of the A2DS2 scale were 0.78 (95 \% CI: $0.73,0.83 ; P=0.00)$ and 0.79 (95\% CI: $0.73,0.84 ; P=0.00$ ), respectively. The study results suggest that the A2DS2 scale has good diagnostic test accuracy and good potency for SAP prognosis. The A2DS2 scale can be used to assess stroke patients' status at an early stage and can distinguish those at high risk of developing stroke-associated pneumonia so that early prophylaxis against strokeassociated pneumonia can be given to high-risk patients. Moreover, the scale can help reduce mortality, the length of stay, and hospital costs in stroke patients. Therefore, the A2DS2 scale can be a feasible clinical tool for the early prediction of strokeassociated pneumonia just before laboratory and imaging evaluations.

In 13 of the 29 studies, the sensitivity was higher than the combination sensitivity, and in 17 studies, the specificity was higher than the combination specificity. No exceptions were made for factors such as ethnicity, study type, and cut-off value. The optimal intercept value of the A2DS2 scale in most studies was 5 , while this value in several studies was 4 [15] or 6 [16]. Changes in the optimal intercept values, such as taking a larger fraction, will reduce its sensitivity and increase the specificity of the A2DS2 scale, while taking a smaller fraction will reduce its specificity and increase the sensitivity. The most appropriate intercept value, which can increase the diagnostic rate for patients with SAP, remains unclear. 


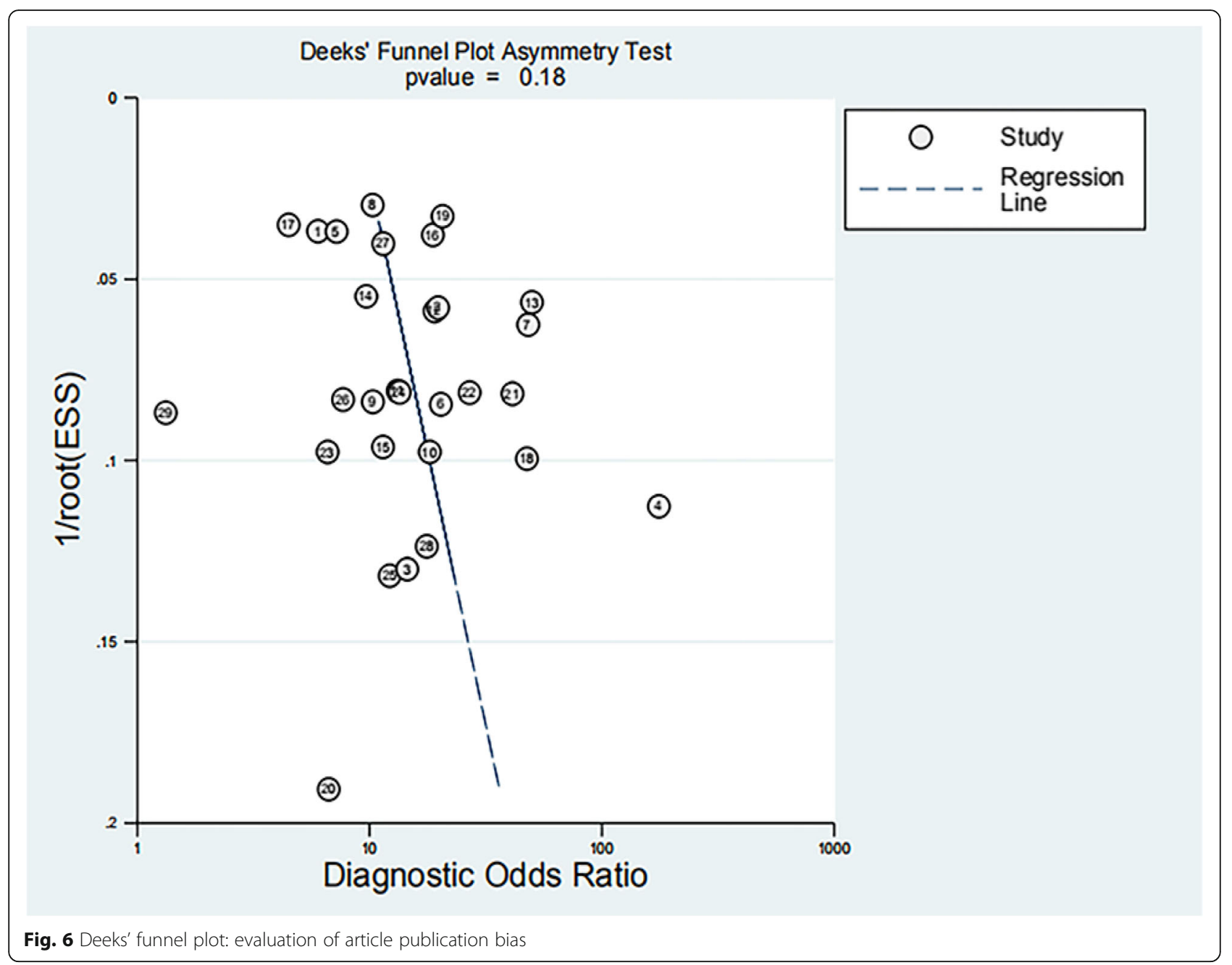

However, in the meta-analysis, the subgroup analysis results confirmed the sensitivity and specificity of the region, study type, sample size, and cut-off value. Subgroup analyses were not significant, except for the cut-off value. The sensitivity and specificity were higher when the cut-off value was equal to 5. Therefore, these results suggest that the A2DS2 scale is a potential prognostic tool that could help clinicians make appropriate treatment decisions and predict the clinical outcome of patients with stroke, especially when the cut-off value is equal to 5 . Sensitivity analysis showed that the merged DOR did not change significantly, which means that the external diagnostic accuracy of the A2DS2 scale was verified. Combined with Fagan nomogram analysis, it was verified that the A2DS2 scale was of high clinical value in diagnosing strokeassociated pneumonia.
Our meta-analysis has several limitations. First, the study's heterogeneity was high $\left(\mathrm{I}^{2}>75 \%\right)$ due to the incompleteness of data, scale usage time, and optimal cut-off value. Second, despite its high sensitivity and specificity, the A2DS2 scale does not entirely exclude false-positive and false-negative rates. Therefore, the A2DS2 scale can be considered only as an SAP screening tool and not a diagnostic tool. The inclusion of those studies may weaken the diagnostic accuracy of the survey to some extent. Third, some high-quality studies were excluded because complete data could not be obtained, and their extensive external adaptability needs to be further verified.

\section{Conclusions}

The A2DS2 scale is a feasible and straightforward scale for the early screening of SAP, with high external 


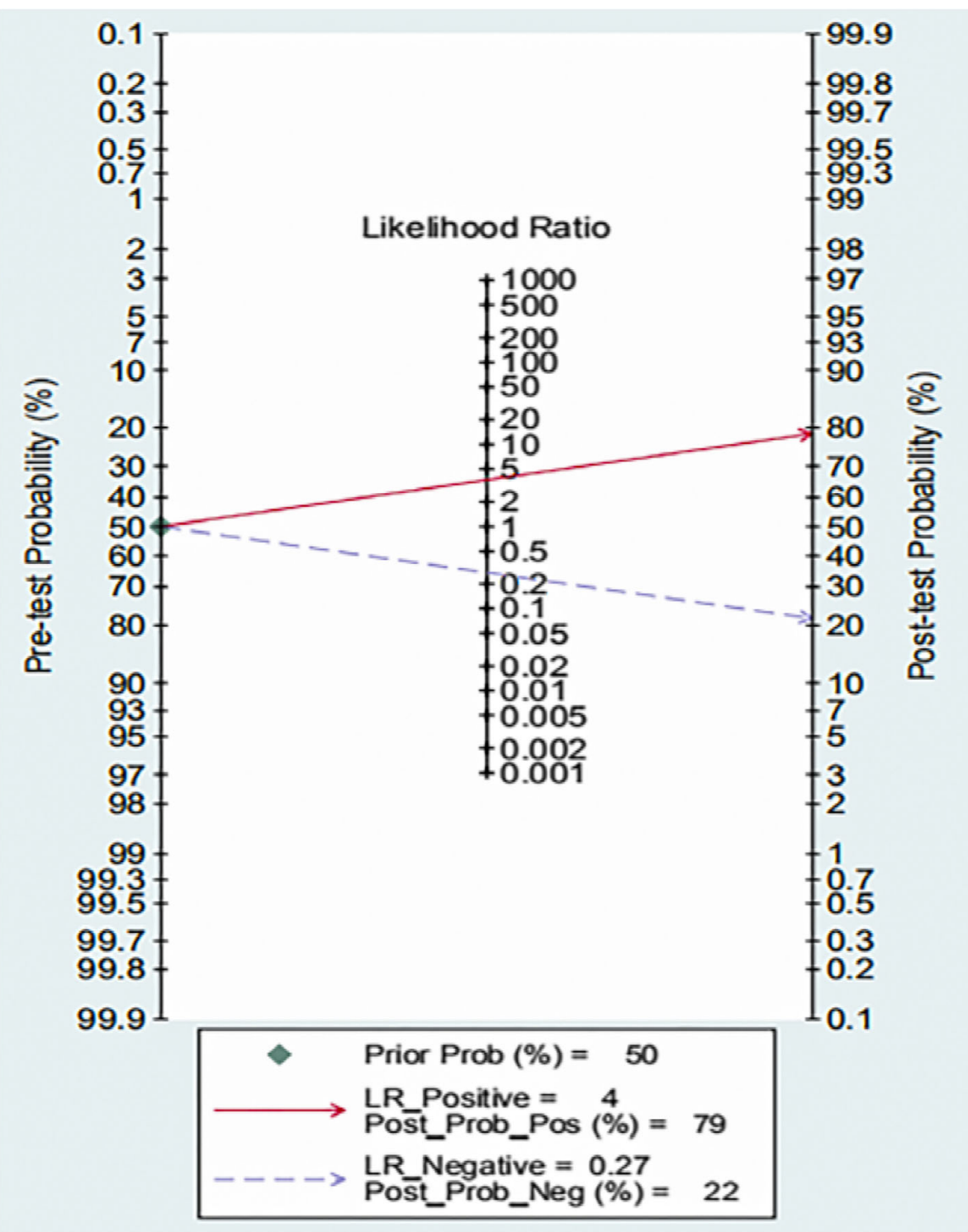

Fig. 7 Fagan nomogram of the clinical applicability of the A2DS2 scale for the diagnosis of SAP

Table 2 Meta-analysis of the diagnostic accuracy of A2DS2 in different subgroups

\begin{tabular}{llcr}
\hline Subgroups & & Sensitivity $\mathbf{( 9 5} \% \mathbf{C l})$ & Specificity $\mathbf{( 9 5} \% \mathbf{C l})$ \\
\hline Study type & retrospective & $0.73(0.68,0.76)$ & $0.82(0.77,0.85)$ \\
& prospective & $0.76(0.72,7.09)$ & $0.79(0.74,0.83)$ \\
Ethnic & Caucasian & $0.75(0.65,0.83)$ & $0.75(0.53,0.89)$ \\
& Asian & $0.76(0.71,0.80)$ & $0.79(0.75,0.84)$ \\
Cut-off value & $<5$ & $0.71(0.65,0.77)$ & $0.76(0.69,0.83)$ \\
& $=5$ & $0.79(0.73,0.84)$ & $0.76(0.68,0.82)$ \\
& $>5$ & $0.75(0.64,0.83)$ & $0.87(0.80,0.91)$ \\
\hline
\end{tabular}


adaptability. A prospective multiregional and largesample study of stroke patients is still needed to verify our results.

\section{Abbreviations \\ QUADAS: Quality Assessment of Diagnostic Accuracy Studies; AUC: Area under the curve; Cl: Confidence interval; SAP: Stroke-associated pneumonia; TP: True positive; FP: False positive; TN: True negative; FN: False negative; PLR: Positive likelihood ratio; NLR: Negative likelihood ratio; DOR: Diagnostic odds ratio; SROC: Summary receiver operating characteristic curve}

\section{Acknowledgements}

Not applicable.

\section{Authors' contributions}

$J H, M L$ and WLH, conducted the literature research, acquired articles and abstracts, interpreted the data, drafted the manuscript, critically revised the manuscript for important intellectual content, and performed the statistical analysis. JMC, FFL and HBW created the study concept and design and critically revised the manuscript for important intellectual content. $J \mathrm{H}, \mathrm{ML}$, WLH, FFL, JMC and HBW read and approved the final manuscript.

\section{Funding}

This study was supported by the National Natural Science Funds for Young Scholars of China (NO. 81801312). The National Natural Science Funds for Young Scholars of China had no role in the design and conduct of the study, collection, management, and analysis of the data.

\section{Availability of data and materials}

All data generated or analysed during this study are included in this published article.

\section{Ethics approval and consent to participate}

Not applicable.

\section{Consent for publication}

Not applicable.

\section{Competing interests}

The authors declare that they have no competing interests.

\section{Author details}

${ }^{1}$ North China University of Science and Technology, Tangshan, Hebei, China. 2Department of Neurology, Hebei General Hospital, 050000 Shijiazhuang, Hebei, China. ${ }^{3}$ Department of Global Health, School of Health Sciences, Wuhan University, Wuhan, Hubei, China.

\section{Received: 7 October 2020 Accepted: 17 January 2021}

\section{Published online: 22 January 2021}

\section{References}

1. Zhang X, Yu S, Wei L, Ye R, Lin M, Li X, et al. The A2DS2 scale as a Predictor of Pneumonia and In-Hospital Death after Acute Ischemic Stroke in Chinese Populations. PLoS One. 2016;11(3):e0150298.

2. Nam KW, Kim TJ, Lee JS, Kwon HM, Lee YS, Ko SB, et al. High Neutrophil to Lymphocyte Ratio Predicts Stroke-Associated Pneumonia. Stroke. 2018;49(8): 1886-92.

3. Chapman C, Morgan P, Cadilhac DA, Purvis T, Andrew NE. Risk factors for the development of chest infections in acute stroke: a systematic review. Top StrokeRehabil. 2018;25(6):445-58.

4. Hoffmann S, Malzahn U, Hendrik H, Hans-Christian K, Koennecke,Klaus B, et al. Berlin Stroke Register and the Stroke Register of Northwest Germany. Development of a clinical score (A2DS2) to predict pneumonia in acute ischemic stroke. Stroke. 2012:43:2617-23.

5. Harms H, Grittner U, Droge H, Meisel A. Predicting post stroke pneumonia: the PANTHERIS score. Acta Neurol Scand. 2013;128:178-84

6. Smith CJ, Bray BD, Hoffman A, Meisel A, Heuschmann PU, Wolfe CD, et al. Can a novel clinical risk score improve pneumonia prediction in acute stroke care? A UK multicenter cohort study. Am Heart Assoc 2015;4.
7. Ji R, Shen H, Pan Y, Wang P,LiuG, Wang Y, et al. China National Stroke Registry Investigators. Novel risk score to predict pneumonia after acute ischemic stroke. Stroke. 2013;44:1303-9.

8. Kishore AK, Vail A, Bray BD, Chamorro A, Napoil MD, Kalra L, et al. Clinical risk scores for predicting stroke-associated pneumonia: A systematic review. Eur Stroke J. 2016:1(2):76-84.

9. Zhang Y. Study on the predictive value of A2DS2 scale combined with blood glucose in the occurrence of acute ischemic stroke associated pneumonia[D]. Shanxi Medical University, 2017.

10. Smth CJ, Kishore AK, Vail A, Chamorro A, Hopkins SJ, DiNapoli M, et al. Diagnosis of stroke - associated pneumonia: recommendations of the consensus group on stroke - associated pneumonia.Fan Linlin, translation; International Journal of Cerebrovasular Diseases: 2016.

11. Smith CJ, Kishore AK, Vail A, Chamorro A, Garau J, Hopkins SJ, et al. Diagnosis of Stroke-Associated Pneumonia: Recommendations From the Pneumonia in Stroke Consensus Group. Stroke. 2015;46(8):2335-40.

12. Consensus of Chinese experts on diagnosis. and treatment of stroke related pneumonia. Chinese J Internal Med. 2010;49(12):1075-8.

13. The neurology branch of the Chinese medical association. The cerebrovascular division of the neurology branch of the Chinese medical association. Chinese guidelines for diagnosis and treatment of acute ischemic stroke. Chinese Society of Neurology. 2015;48(4):246-57.

14. Whiting P, Rutjes A, Westwood M, et al. QUADAS-2: a revised tool for the quality assessment of diagnostic accuracy studies. Ann Intern Med. 2011; 155(8):529-36.

15. Li Y, Zhang Y, Ma L, Niu X, Chang J. Risk of stroke-associated pneumonia during hospitalization: predictive ability of combined A2DS2 score and hyperglycemia. BMC Neurol. 2019;19(1):298

16. Ren XY, Yuan HY, Huang K, Fu M. A2DS2 scale predicted stroke associated pneumonia in patients with precirculatory and postcirculatory ischemic stroke. Int J Cerebrovas Dis. 2019;27(6):419-25.

17. Yang R, Li H, Wang XP, Mi JW, Meng QL, Yuan YJ, et al. The accuracy of A2DS2 and ais-aps scores in predicting stroke-related pneumonia was compared. Contemporary Med. 2019;25(9):164-6.

18. Mao BY, Guo Y, Liu LL, Yu RM, Yang X, Cao JH, et al. Clinical study on A2DS2 scale combined with procalcitonin to predict early stroke associated pneumonia. Med Philo. 2018;39(4):43-6

19. Pi CX, Li P, Gao J. A2DS2 scale was used to analyze the risk factors of stroke related pneumonia and related nursing strategies. Clin Res Pract. 2019;4(1): 98-100.

20. Wang N, Li PL. Application of A2DS2 scale in predicting acute ischemic stroke associated pneumonia. Clin Focus. 2018;33(8):683-6.

21. Hang J, Pan XD, Ge NN, Yang Y, Zhou JS, Tian YY. Prediction of strokeassociated pneumonia in patients with ischemic stroke: a comparison of 6 scores. Int J Cerebrovasc Dis. 2017:25(11):972-8.

22. Luo XN, Liu XS, Wang K, Li SG, Chen JB, Feng LJ, et al. Comparison of the predictive value of two scales to acute ischemic stroke associated pneumonia. Chinese J Geriatr Heart Brain Vessel Dis. 2018;20(11):1183-6.

23. Zhang YP, Yang AM. Performance of A2DS2 scale and Ais-Aps score In predicting stroke-associated pneumonia. J Cardiovardiovasc Pulmon Dis. 2019;38(6):624-8.

24. Shan $Y$, Chen DQ. Comparison of predictive effects of different stroke related pneumonia prediction scales in patients with ischemic stroke. J Nurs. 2018;25(24):43-6.

25. Yuan Y. Risk factors and predictive value of ISAN and A2DS2 scales for acute ischemic stroke associated pneumonia in xining area. Qinghai University. 2018.

26. Yang JF. Risk factors and the predictive value of A2DS2 scale for acute ischemic stroke associated pneumonia. Xinjiang Medical University. 2014.

27. Shang YC, Wang SH, Bai XJ, Gao ZB, Li JM, Wu WP, et al. A2DS2 scale was used to predict the risk factors of pneumonia after stroke in elderly population. J Southern Med Univ. 2013;33(11):1615-9.

28. Li YP, Song B, Fang H, Gao Y, Zhao L, Xu YM. External validation of the A2DS2 scale to predict stroke-associated pneumonia in a Chinese population: a prospective cohort study. PLoS One. 2014;9(10):e109665.

29. Gong SY, Zhou ZW, Zhou MK, Lei Z, Guo J, Chen N. Validation of risk scoring models for predicting stroke-associated pneumonia inpatients with ischaemic stroke. Stroke Vasc Neurol. 2016;1(3):122-6.

30. Lu Y, Liu XY, Chen YJ, Yu J, Yin SJ. Serum iron and A2DS2 scale in strokeassociated pneumonia. Int J Clin Exp Med. 2015;8(4):6163-70.

31. Li L, Zhang LH, Xu WP. Hu JM. Risk assessment of ischemic stroke associated pneumonia. World Journal of Emergency Medicine. 2014; 5(3). 
32. Batubara CA. Hubungan Skor Klinis A2DS2 (Age, Atrial Fibrillation, Dysphagia, Sex And Stroke Severity) Terhadap Kejadian Pneumonia Pada Penderita Stroke Akut[]]. 2015.

33. Limesh V, Dinkar K, Pradeep M, Ajai S, Abdul Q, Anup T. A2DS2 scale to Predict the Risk of Stroke-Associated Pneumonia in Acute Stroke: An Indian Perspective. Neurosci Rural Pract. 2019;10:465-71.

34. Tu TM, Phua SS, Acharyya S, Ng WM, Oh DC. Predicting Pneumonia in Acute Ischaemic Stroke:Comparison of Five Prediction Scoring Models. Ann Acad Med Singapore. 2017;46(6):237-44.

35. Zapata AE, Moniche F, Blanca PG, Bustamante A, Escudero MI, Ucles O External Validation of the ISAN, A2DS2, and AIS-APS Scores for Predicting Stroke-Associated Pneumonia. J Stroke Cerebrovasc Dis. 2017;27(3):673-6.

36. Ramírez-Moreno JM, Martínez-Acevedo M, Cordova R, Roa AM, Muñoz P. External validation of the A2SD2 and ISAN scales for predicting infectious respiratory complications of ischaemic stroke. Neurología. 2016.

37. Yota K, Daisuke I, Naohito N, Hiroshi M, Takumi Y, Tomohide A, et al. Predictors of Pneumonia Complications in Patients with Acute Stroke Requiring Basic Mobility Assistance. Rigakuryoho Kagaku. 2019;34(3):325-30.

38. Cugy E, Sibon I. Stroke-Associated Pneumonia Risk Score:Validity in a French Stroke Unit. J Stroke Cerebrovasc Dis. 2017;26(1):225-9.

39. Tamer AH, Mohamed AA, Mohammed A. Prediction of Ischemic Stroke -Associated Pneumonia: A Comparison between 3 Scores. J Stroke Cerebrovasc Dis. 2016;25(11):2756-61.

40. Elhasina H, Szolicsa M, Hassana A, Soliman N, Kaasch A. Risk scores for predicting stroke associated pneumonia: Validity of A2DS2 and ISAN scores. J Neurol Sci. 2019:405S:104163.

41. Almeida SR, Bahia MM, Lima FO, Paschoal IA, Cardoso TA, Li LM. Predictors of pneumonia in acute stroke in patients in an emergency unit. Arq Neuropsiquiatr. 2015;73(5):415-9.

\section{Publisher's Note}

Springer Nature remains neutral with regard to jurisdictional claims in published maps and institutional affiliations.

Ready to submit your research? Choose BMC and benefit from:

- fast, convenient online submission

- thorough peer review by experienced researchers in your field

- rapid publication on acceptance

- support for research data, including large and complex data types

- gold Open Access which fosters wider collaboration and increased citations

- maximum visibility for your research: over $100 \mathrm{M}$ website views per year

At $\mathrm{BMC}$, research is always in progress.

Learn more biomedcentral.com/submissions 